\title{
An overview of the question-response system in Japanese
}

\author{
Makoto Hayashi *
}

University of Illinois at Urbana-Champaign, Department of East Asian Languages and Cultures, 2090 Foreign Languages Building, 707 South Mathews Avenue, Urbana, IL 61801, USA

\section{A R T I C L E I N F O}

\section{Article history:}

Received 4 February 2010

Accepted 1 April 2010

\section{Keywords:}

Questions

Answers

Formulations

Actions

Fittedness

Japanese

\begin{abstract}
A B S T R A C T
Based on an examination of 350 question-response pairs identified across 10 different video-taped, face-to-face interactions among native speakers of Japanese, this paper presents an overview of the question-response system in Japanese conversation. Its descriptions focus on the lexical/morphosyntactic/prosodic resources used for question formulation, the range of action types commonly performed with question-formatted utterances, the kinds of methods used for next speaker selection, and the patterns of fittedness between questions and their responses.
\end{abstract}

(c) 2010 Elsevier B.V. All rights reserved.

\section{Introduction}

This paper provides an overview of the question-response system in Japanese based on the data collected for the comparative question-response coding project. The data consist of 350 instances of questions identified across 10 different video-taped, face-to-face interactions among native speakers of Japanese. To avoid selective sampling, the first 35 instances of questions were gathered from each of the ten recordings. The interactions examined are maximally informal, spontaneous conversations among 3-4 adult friends and/or family members. The participants consist of 26 female speakers and 10 male speakers, and their age range is 25-55. Because morphosyntactic markings of questions appear to vary across different dialects of Japanese, as much effort as possible was made to include only those interactions whose participants are speakers of the Tokyo-based, kyootsuugo (common language) variety of Japanese. Though some regional features were detected in the speech of several participants, no discernible effect of dialectal variation was observed in the instances of questions (and responses to them) collected.

The description provided in this paper focuses on "functional questions" $(n=320)$, i.e., those questions that are produced to seek information, confirmation, or agreement rather than those that are interrogatively formatted but do not appear to seek a response (e.g., rhetorical questions). The following section discusses the results of the present study, focusing on lexical/grammatical/prosodic resources used for formulating functional questions in Japanese (section 2.1), the range of social actions performed by speakers using these different structural resources (section 2.2), the methods used by questioners to select who should respond to their questions (section 2.3), and the patterns of fittedness between questions and responses to them-i.e., whether a response supplies an answer or not, whether answers are 'type-conforming' (Raymond, 2003) or not, etc. (section 2.4). The paper closes with brief concluding remarks.

\footnotetext{
* Tel.: +1 217333 7036; fax: +1 2172442223.

E-mail address: mhayashi@illinois.edu.
} 
Table 1

Distribution of different types of questions.

\begin{tabular}{ll}
\hline Question type & Percentage \\
\hline Polar & $85 \%(n=274)$ \\
Q-Word & $15 \%(n=47)$ \\
Alternative & $<1 \%(n=1)$ \\
Total & $100 \%(n=322)$ \\
\hline
\end{tabular}

Table 2

Distribution of different sub-types of polar questions.

\begin{tabular}{ll}
\hline Polar Q. type & Percentage \\
\hline Interrogative & $31 \%(n=85)$ \\
Declarative & $39 \%(n=108)^{\mathrm{a}}$ \\
Tag & $30 \%(n=81)$ \\
Total & $100 \%(n=274)$ \\
\hline
\end{tabular}

a $69 \%(n=74)$ of the declarative-type questions are marked prosodically through the use of rising intonation at the end of the declaratively-formatted utterance, while the remaining $31 \%(n=34)$ do not employ any morphosynctactic or prosodic resources for question formulation. See section 2.1.1.2.

\section{Results}

\subsection{Lexical/grammatical/prosodic resources for question formulation}

As is the case with most of the languages examined in this project, there are three major types of question formats observed in the Japanese corpus: polar (i.e., 'yes/no'-type) questions, Q-word (i.e., 'wh'-type) questions, and alternative questions. The overall distribution of these question types in the current data is presented in Table 1.

Polar and Q-word questions thus account for all the functional questions except for one case, with polar questions occurring nearly 6 times more frequently than Q-word questions. For polar and Q-word questions, we also observe a number of subtypes that are formulated with different lexical/grammatical/prosodic resources. Below I illustrate these subtypes with examples from the data and provide information regarding their distribution.

\subsubsection{Polar questions}

In the current data, I identified three major types of turn-designs used to formulate polar questions in Japanese: the interrogative type, the declarative type, and the tag-question type. The distribution of these three types of polar questions observed in the current data is presented in Table 2.

2.1.1.1. Interrogative type: use of sentence-final 'question particles'. Unlike languages like English, in which the default method of forming an interrogative sentence is to use syntactic inversion, the default method (or at least what conventional grammars regard as the default method) of constructing an interrogative sentence in Japanese is to use a sentence-final 'question particle' that indicates that the sentence it attaches to is a question (Kuno, 1973; Shibatani, 1990; Iwasaki, 2002). In the current data, this type of polar questions accounts for $31 \%$ of all polar questions.

The particles $k a$ and no are the two most common particles used as question particles in the data. Generally speaking, $k a$ is used when the predicate (e.g., verb) of the sentence is in the polite form, as in (1), where the copula is in the polite form, desu. When the predicate of the sentence is in the non-polite, plain form, e.g., $i i$ 'good' in (2), the particle no is used. ${ }^{1}$

(1) [J008002] ((To a co-participant who said that he is not good at getting up in the morning.))

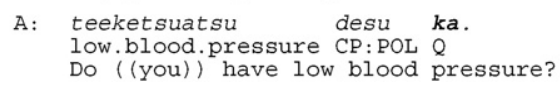

(2) [J009014] ((K, who has never used electronic airline tickets, asks about how to use them.))

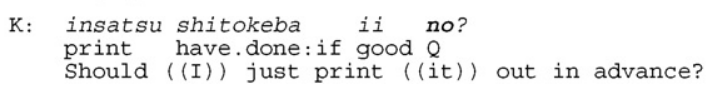

\footnotetext{
${ }^{1}$ It is not impossible to use $k a$ after the non-polite, plain form of a predicate, or to use no after the polite form of a predicate, to formulate questions in Japanese. However, neither of these combinations is found in the 74 instances of polar questions formed with the sentence-final particles ka and no observed in the current data (there are two cases in which both no and $k a$ in that order follow the plain form of a predicate). Using $k a$ after the plain form of a predicate sounds somewhat coarse, and female speakers are said to avoid it. Using no after the polite form of a predicate, on the other hand, is often regarded as a feature of strongly feminine speech style (Iwasaki, 2002:302).
} 
Note that the only lexico-morphosyntactic difference between the questions in the examples above and their corresponding declarative sentences is the presence/absence of the sentence-final question particles. Thus, for instance, if one were to omit the sentence-final $k a$ from the question in (1), one would have a declarative sentence, i.e., teeketsuatsu desu. '((I/you/he/she/ we/they)) have/has low blood pressure.'

With regard to prosody, both $\mathrm{ka}$-marked and no-marked polar questions are produced either with a rising intonation or with a flat to falling intonation at the end of the sentence. In the current data, no-marked questions are more likely to be produced with a rising intonation ( $72 \%$ of all no-marked questions) than $\mathrm{ka}$-marked questions ( $41 \%$ of all $\mathrm{ka}$-marked questions).

There is one other sentence-final particle worth noting here. Seven cases are found in the current data in which polar questions were formed with the particle kke. Martin (1975) calls it a 'retrospective particle', which denotes “thinking back, recollecting to oneself, or questioning oneself about some situation to be recalled” (p. 937). While Martin's characterization focuses on self-addressed usage of kke, in conversation the particle is commonly used in utterances addressed to another participant. A typical situation in which kke is used in the current data is one in which the speaker solicits help from the addressee in remembering something that the speaker once knew, but apparently has forgotten or is unsure about now. The following example illustrates this.

(3) [J009022] ((The participants discussing one another's visas to stay in the United States.))

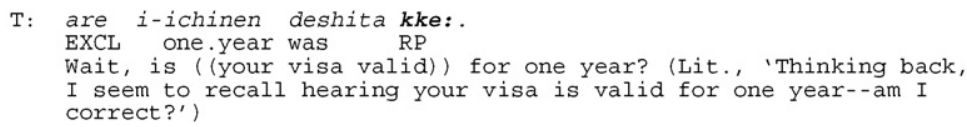

Thus, unlike ka and no, kke makes implicit reference to knowledge or information previously held by the speaker and shared with the addressee, but which the speaker has somehow forgotten or is unsure about. The particle then serves to enlist collaborative participation of the addressee in the process of regaining that knowledge/information.

2.1.1.2. Declarative type: use of rising intonation and/or 'B-event' statements. In spontaneous conversation, declarativelyformatted utterances without morphosyntactic interrogative marking (e.g., question particles) are nonetheless used as "questions" quite often. In the current data, these "declarative questions" account for 39\% of all polar questions.

There are two major types of resources (which are not mutually exclusive) used to formulate declarative questions. One is to use rising intonation at the end of a declaratively-formatted utterance, as in (4). In this type of question, only prosody distinguishes the question from its declarative counterpart.

(4) [J004004]

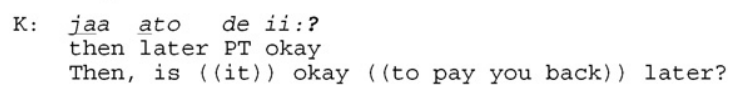

These prosody-based questions are built not only with fully-fledged declarative sentences, but also with 'sentence fragments' or phrasal utterances, as seen in (5).

(5) [J006009] ((Participants are discussing college classes they have taken. 'BTW' refers to a course rubric and '250' refers to a course number.))

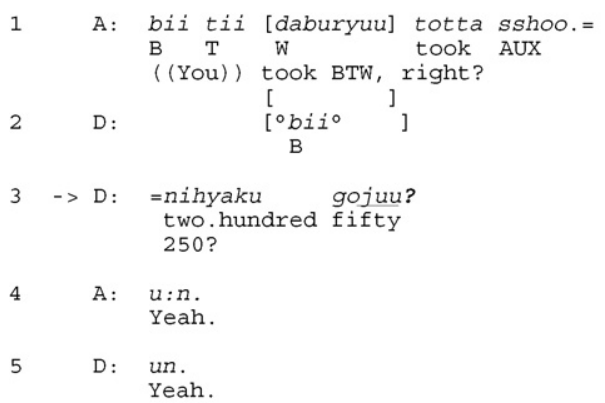

As illustrated by this example, prosody-based phrasal questions are typically used for an 'understanding check', i.e., as a way to check the speaker's understanding of the previous speaker's utterance.

Another resource for formulating declarative questions is to use B-event statements (Labov and Fanshell, 1977), which are "declarative utterances in which the speaker formulates some matter as one to which the recipient has primary access" (Heritage and Roth, 1995:10). By making claims about a matter within the addressee's domain of knowledge, such an utterance makes the addressee's confirmation or disconfirmation relevant in the next turn. While some B-event statements are produced with a rising intonation at their end, others ( $n=34 ; 31 \%$ of all declarative questions) do not employ any morphosynctactic or prosodic resources for question formulation. These non-prosody-based B-event statements are thus 
formally indistinguishable from declarative sentences and can be regarded as "questions" from a function-only perspective. The following fragment presents an example.

(6) [J007004] ((K vaguely remembers that one of the co-participants dislikes beer, but she says that she can't remember who it was. M claimed that none of them dislikes beer and asks if $\mathrm{K}$ is in fact talking about herself.))

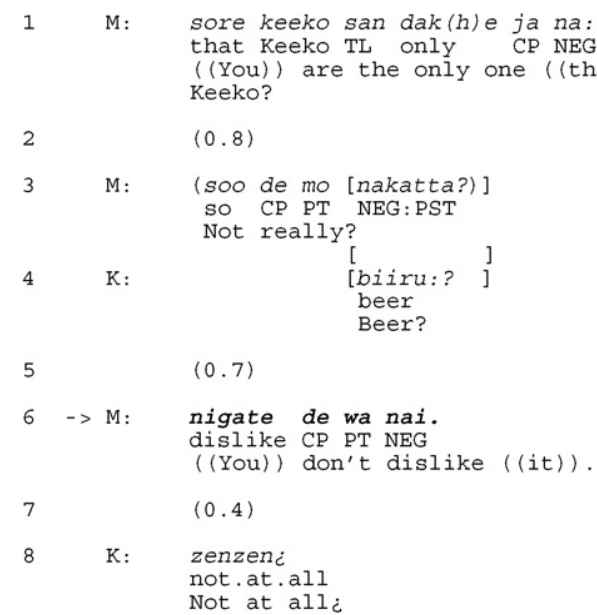

Here, M's declaratively-formatted utterance in line 6 addresses a matter to which the addressee, $\mathrm{K}$, has primary access, and it makes K's confirmation or disconfirmation relevant in the next turn (line 8).

It is worth noting that, of the 34 cases of non-prosody-based B-event statements found in the current data, one third ( $n=11$ ) employ the same sentence-final expression, $n d a$ (nominalizer $n+$ copula $d a$ ), as seen in (7).

(7) [J010033] ((The participants are discussing N's commuting situation. The 'commuting hell' refers to having to ride overcrowded commuter trains, which is a common situation in large cities in Japan.))

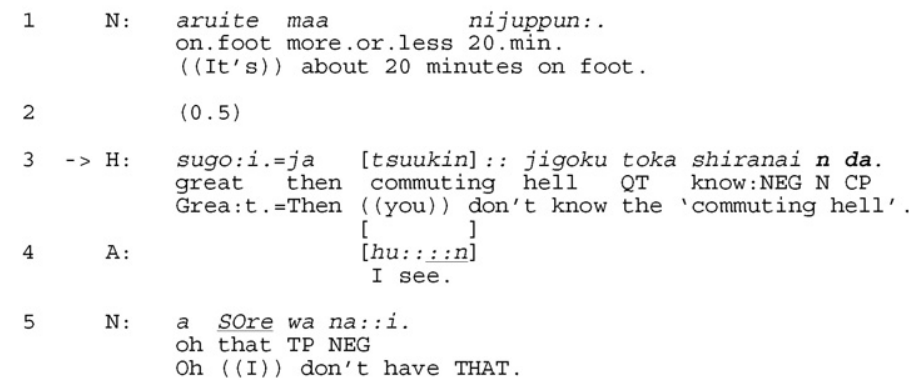

While the varied functions of the sentence-final $n$ da have been studied extensively in Japanese linguistics (e.g., Kuno, 1973; McGloin, 1980; Maynard, 1992; Iwasaki, 1993; to name a few), no study, as far as I am aware, has offered an account for its usage in B-event statements as illustrated above. It appears that $n d a$ is used in this type of utterance to register newly acquired knowledge or realization as noteworthy.

2.1.1.3. Tag-question type. The third type of polar questions discussed here is those with tag-like endings. This type of question accounts for $29.6 \%$ of all polar questions in the data. Included in this category are utterances with a variety of sentence-final expressions that are used to seek the addressee's agreement or confirmation to the proposition asserted in the preceding part of the sentence. In the current data, I identified three major types of tag-like sentence-final expressions: the 'grammaticalized negative expression' (Iwasaki, 2002:283) janai and its variants, the modal auxiliary deshoo, and the combination of sentence-final particles yo and $n e$ in that order. ${ }^{2}$

\footnotetext{
${ }^{2}$ While tag-question-like expressions discussed here and the question particles described in section 2.1.1.1 occur in sentence-final position, there are some crucial differences between the two. First, as mentioned above, tag-question-like expressions are functionally specialized for seeking agreement or confirmation to the proposition asserted, while questions particles are not. Second, question particles can and do occur with Q-word questions, while tagquestion-like expressions cannot, perhaps due to the fact that one could not seek agreement or confirmation with a Q-word question. Third, tag-questionlike expressions can occur by themselves in a turn at talk (though not very commonly) to seek agreement or confirmation to an assertion made in the preceding turn, while question particles cannot be used in such a 'stand-alone' manner. These facts provide sufficient grounds to treat tag-question-like expressions separately from question particles.
} 
Grammaticalized negative expression janai and its variants

Janai consists of the copulative expression $j a^{3}$ and the negative morpheme nai. Rather than contributing to the propositional content of the sentence to which it is attached, janai functions as a sentence extension seeking agreement/ confirmation from the addressee. Its truncated form, jan, and the polite equivalent, ja nai desu ka, are also found in the data.

(8) [J008032] ((The participants have been debating whether body temperature goes up or down when one falls asleep. Here, $\mathrm{S}$ is responding to $\mathrm{A}$, who has claimed that body temperature has to go down for one to fall asleep.))

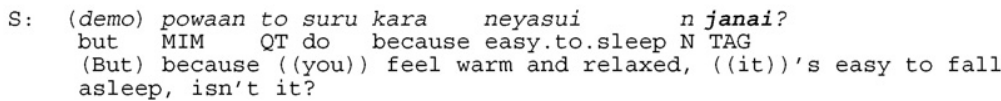

(9) [J006005] ( $(\mathrm{C}$ has asked $\mathrm{A}$ if a 1.5-page writing assignment that $\mathrm{A}$ has to do for her class is to be hand-written on the Japanese-style manuscript paper called genkooyooshi (400 characters per page) or to be typed on regular paper (1,500+ characters per page).))

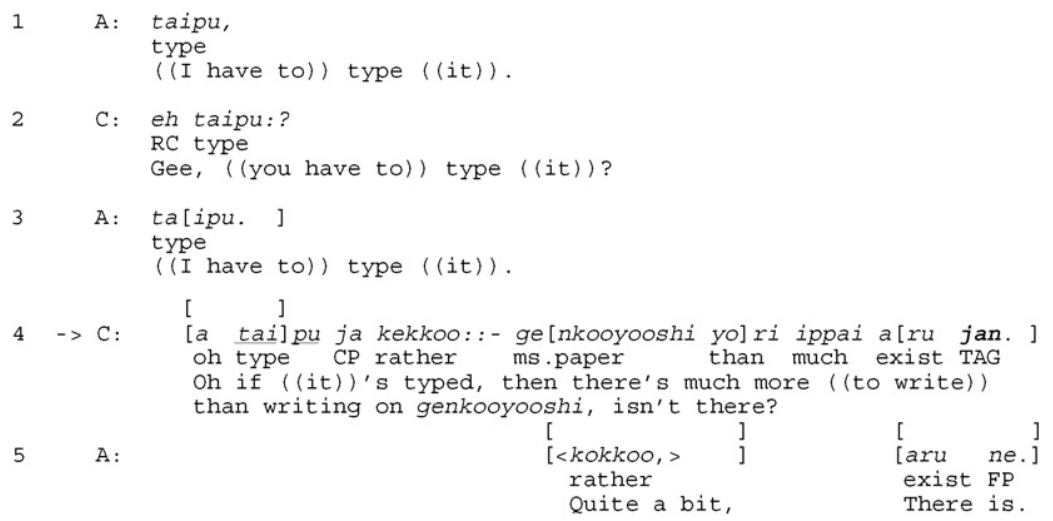

(10) [J003006] ((The participants are looking at photos from their recent trip.))

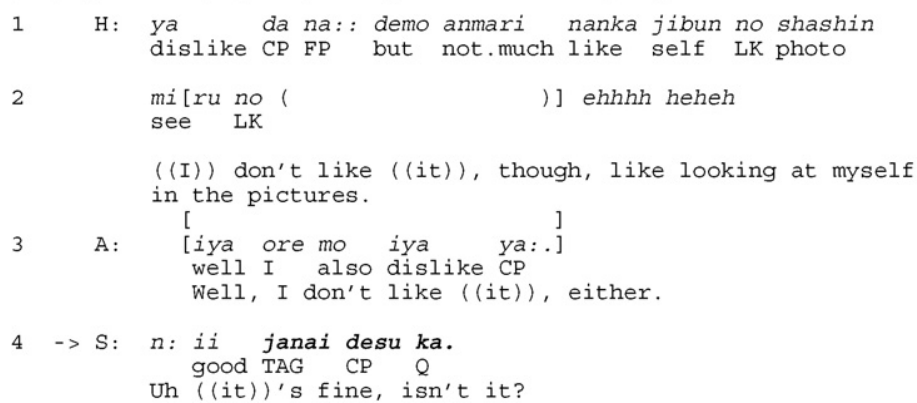

Modal auxiliary deshoo

Deshoo and its plain-form equivalent daroo are often described as auxiliaries of conjecture ('probably', 'I think'; Makino and Tsutsui, 1986). When used with rising intonation, they ask for the addressee's confirmation to the speaker's conjecture being presented. The following example illustrates this use of deshoo (no instance of daroo was found in the current data).

(11) [J005024] ((T, who has never been to India, is speaking to a couple that used to live there for several years.))

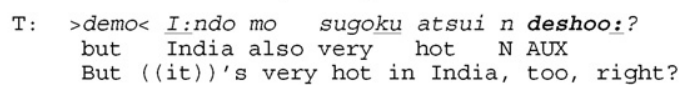

Presenting (and seeking confirmation to) the speaker's conjecture does not seem to be the only function of deshoo, however. There are a number of cases in the current data in which deshoo is used to present a proposition that the speaker already knows for a fact. In such cases, deshoo does not so much seek confirmation to conjecture as to seek agreement to the proposition being presented. This is illustrated by the following example.

\footnotetext{
${ }^{3}$ To be more precise, $j a$ is the contracted form of $d e w a$ (the continuative form of the copula de followed by the topic particle wa).
} 
Table 3

Distribution of different sub-types of tag-type questions.

\begin{tabular}{ll}
\hline Tag question type & Percentage \\
\hline Grammaticalized negative expressions (janai, etc.) & $30.9 \%(n=25)$ \\
Modal auxiliary deshoo & $22.2 \%(n=18)$ \\
Final particles yo ne & $40.7 \%(n=33)$ \\
Other & $6.2 \%(n=5)$ \\
Total & $100.0 \%(n=81)$ \\
\hline
\end{tabular}

(12) [J007019] (( $\mathrm{K}$ is explaining to $\mathrm{M}$ how to prepare filling for dumplings.))

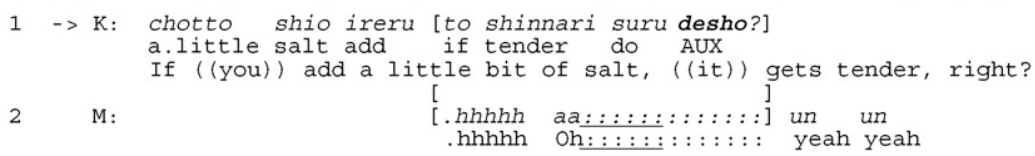

\section{$\underline{\text { Particles yo ne }}$}

Yo is often described as a particle that marks the speaker's assertion, while ne is commonly glossed as a particle indicating the speaker's request for confirmation or agreement (Makino and Tsutsui, 1986). Together, these particles are used sentencefinally to make an assertion while seeking confirmation/agreement to it from the addressee.

(13) [J002003] ((The participants are eating some kind of sweets that they are not familiar with, and they are trying to guess what it is.))

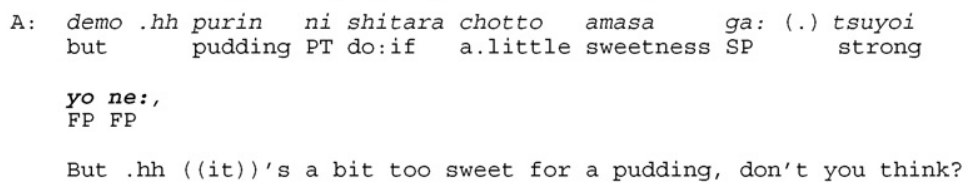

Most grammatical descriptions of Japanese do not treat sentences ending with yo ne as questions. I included them here as a type of polar questions because they fulfill the functional criterion used to define questions in our project-i.e., that the speaker's utterance makes the provision of information, including confirmation/disconfirmation and agreement/disagreement, a relevant next action by the addressee.

Table 3 shows the distribution of the sub-types of tag-type questions.

\subsubsection{Q-word questions}

As a notable feature of Q-word questions in Japanese, it is often pointed out that the Q-word appears in situ, i.e., in the position in which the constituent supplying the requested information would appear in the corresponding declarative sentence, rather than being moved to sentence-initial position as observed in Q-word questions in English (Kuno, 1973; Iwasaki, 2002). This is illustrated by the following constructed sentences.
a. Ken wa Marini yubiwa o katte-agemashita.
Ken TP Mari for ring $O$ buy-gave:POL
Ken bought a ring for Mari.
b. Ken wa Marini nani o katte-agamashita ka. Ken TP Marifor what $\mathrm{O}$ buy-gave:POL Q What did Ken buy for Mari?

Interestingly, however, in the current data the Q-word does appear in sentence-initial position in $65 \%$ of all questions containing Q-words (28 out 43 cases). In many cases, this is due to the fact that constituents other than the Q-word are left unexpressed because they are recoverable from the context (i.e., so-called 'zero-anaphora', which is the default type of reference used for non-initial mentions in Japanese discourse; see Clancy, 1980; Hinds, 1982). This is not surprising because, in conversation, many questions are produced in response to a co-participant's prior utterance, and in such situations, the syntax of the question utterance tends to be 'parasitic' on the syntax of the prior utterance that has prompted the question. The following fragment illustrates this. 
(15) [006020]

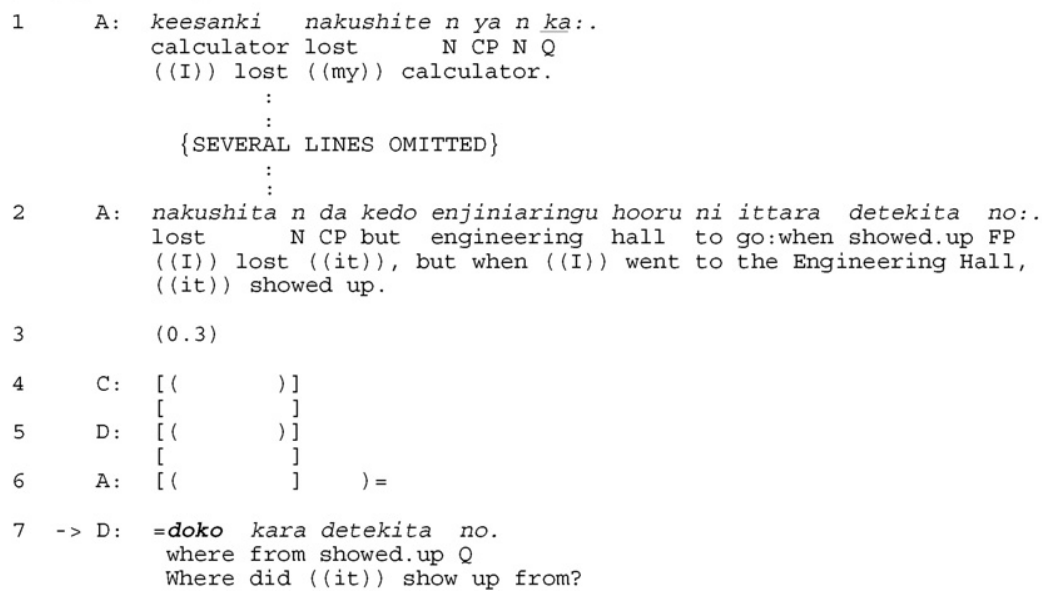

If the question in line 7 were produced with an overt mention of the subject of the sentence, for example, with the demonstrative sore 'that one', then the Q-word doko may not appear in sentence-initial position (sore doko kara detekita no).

In other cases where a Q-word is employed at the beginning of the question, its sentence-initial placement appears to be a result of either the fronting of the Q-word or the post-posing of other constituents that would appear sentence-initially. The following example illustrates the latter.

(16) [J001020] ((Y has been using a friend's bicycle to go to work, but she will have to return it to the friend soon.))

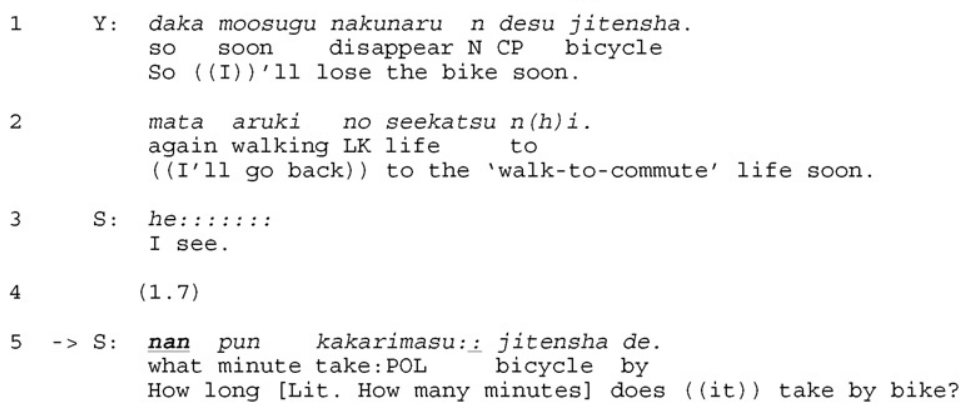

In the question in line 5, the instrumental phrase jitensha de 'by bicycle' is placed in post-predicate position. In a more standard word order, jitensha de would be placed before the sentence-final predicate, such as in jitensha de nan pun kakarimasu?.

Although it is inconclusive from the data at hand, it might be interesting to explore whether there is an orientation to placing Q-words in sentence-initial positions, and if there is, what motivates it.

With regard to the distribution of different types of Q-word questions in the current data, we have the following statistics (Table 4).

Table 4

Distribution of different types of Q-word questions.

\begin{tabular}{ll}
\hline Q-word question type & Percentage \\
\hline 'Who'-type (Person) & $9 \%(n=4)$ \\
'What'-type (Object) & $2 \%(n=1)$ \\
'What'-type (Event) & $17 \%(n=8)$ \\
'What'-type (Prior Talk) & $21 \%(n=10)$ \\
'Which'-type (Object) & $4 \%(n=2)$ \\
'Which'-type (Event) & $2 \%(n=1)$ \\
'What kind'-type (Object) & $9 \%(n=4)$ \\
'Where'-type (Place) & $13 \%(n=6)$ \\
'When'-type (Time) & $0 \%(n=0)$ \\
'Why'-type (Reason) & $6 \%(n=3)$ \\
'How'-type (Manner) & $11 \%(n=5)$ \\
'How many/much'-type (Amount) & $6 \%(n=3)$ \\
Total & $100 \%(n=47)$ \\
\hline
\end{tabular}


It is unclear why no instance of the 'when'-type question was found in the data, as they are not an uncommon type of Q-word question.

Below I illustrate each type of Q-word question with an example from the data. For the 'when'-type question, I present an example from a transcript not used for this study.

\section{'Who'-type (Person)}

(17) [J006010] ((slightly extended version of fragment (5) above))

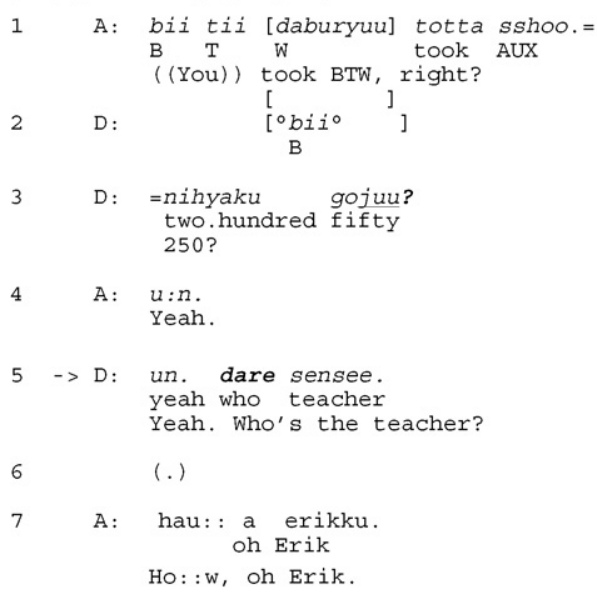

\section{'What'-type (Object)}

(18) [J004029] ((The participants are choosing what cake to eat.))

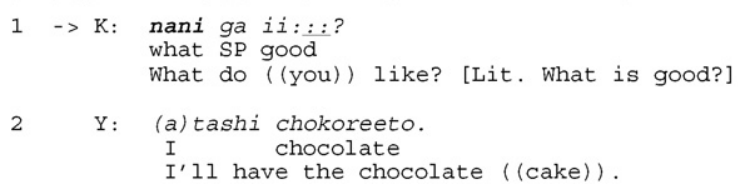

\section{'What'-type (Event)}

(19) [J001009]

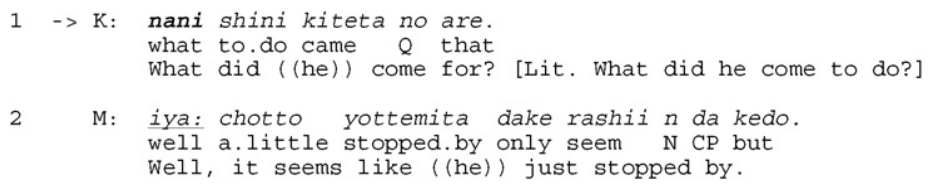

'What'-type (Prior Talk)

(20) [J004017] ((Students studying in the US are discussing the 'Optional Practical Training' (OPT) visa to work in the US after graduation.))

1

K: oopitii wa >shigoto nakutemo< ii tte yutteta: :=
OPT TP job not.have:even.if okay QT were.saying

((They)) were saying that if ((you)) have an OPT, it's okay ((to

stay in the US)) without a job.

2

$\mathrm{Y}:=>$ oopitit wa shigoto ga nakutemo ii [n da.<]

Oh if ((you)) have an OPT, it's okay ((to stay in the US))

without a job, I see.

$3 \mathrm{R}$ :

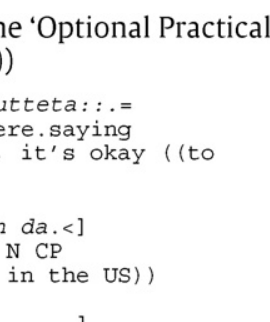




\section{'Which'-type (Object)}

(21) [J004027] ((The participants are choosing which cake to eat.))

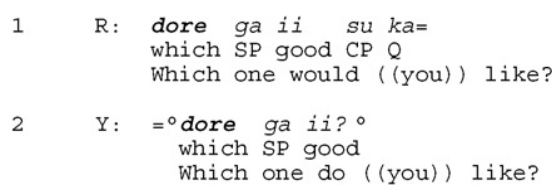

\section{'Which'-type (Event)}

(22) [J003014] ((Looking at a photo from a recent trip.))

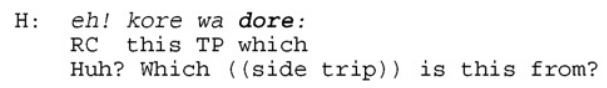

\section{'What kind'-type (Object)}

(23) [J007015] ((Discussing how to make dumplings.))

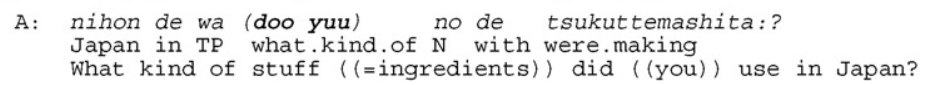

\section{'Where'-type (Place)}

(24) [J003027] ((Looking at a photo from a recent trip.))

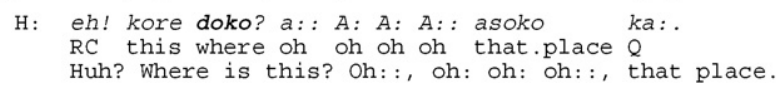

\section{'When'-type (Time)}

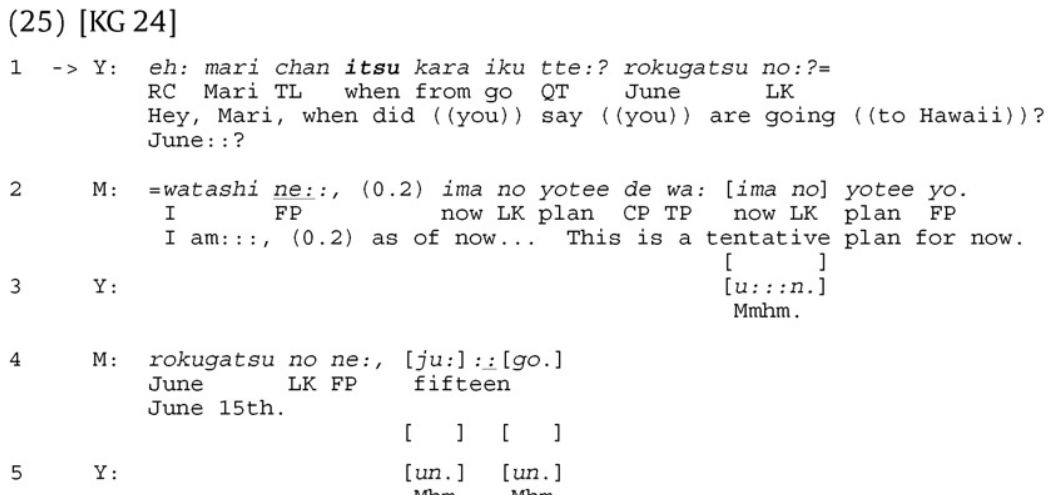

'Why'-type (Reason)

(26) [J009018]

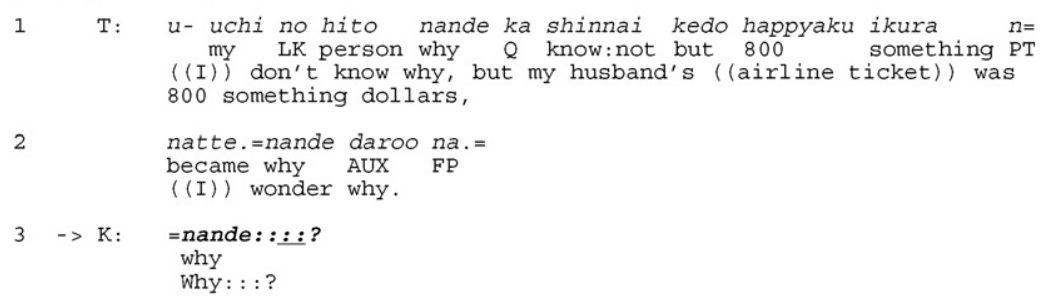


‘How'-type (Manner)

(27) [J005005] ((T and K moved from a mid-size city to a small town, and S asks them how the city they used to live in compares to where they live now.))

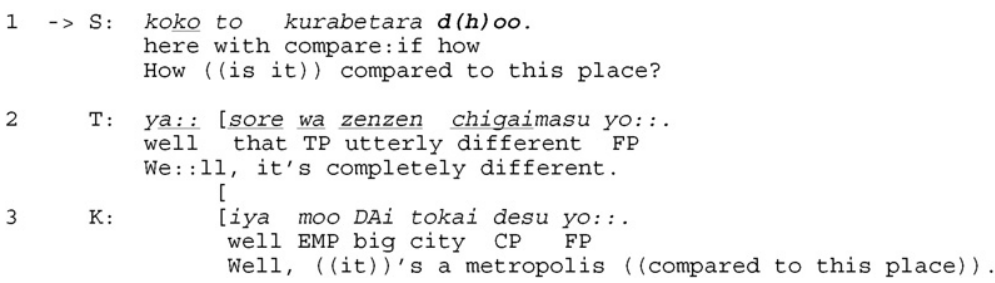

'How many/much'-type (Amount)

(28) [J009016] ((T and $\mathrm{K}$ are discussing airfare.))

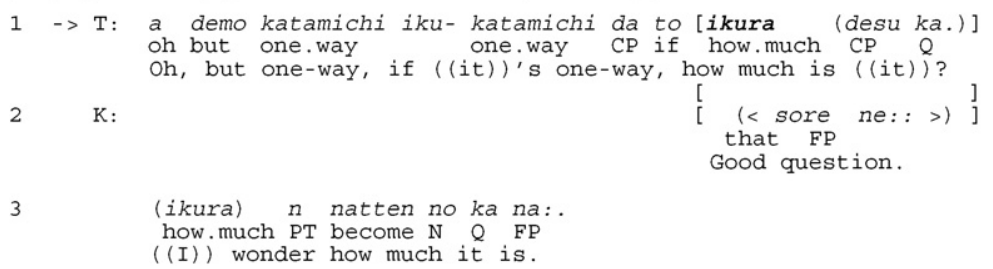

On a final note in this subsection, I should mention that some of the morphosyntactic and prosodic resources used for the formulation of polar questions discussed in the previous subsections are also observed for the formulation of Q-word questions. The sentence-final particles $k a$ (e.g., (28)) and no (e.g., (19)), as well as rising intonation (e.g., (18)), are used in some (but not all) of the Q-word questions identified in the current data.

\subsubsection{Alternative questions}

As there is only one example of alternative question in the data, not much can be said about their structural properties. I only note here that, just as in alternative questions in English, the alternatives are presented in juxtaposition for the addressee to choose one. In the following example, guuzen 'by chance' and hitsuzen 'necessity' are presented side-by-side (line 2) and the addressee is asked to choose one.

(29) [J003004] ((The participants are discussing the arrangement of photos in the photo album that they are looking at.))

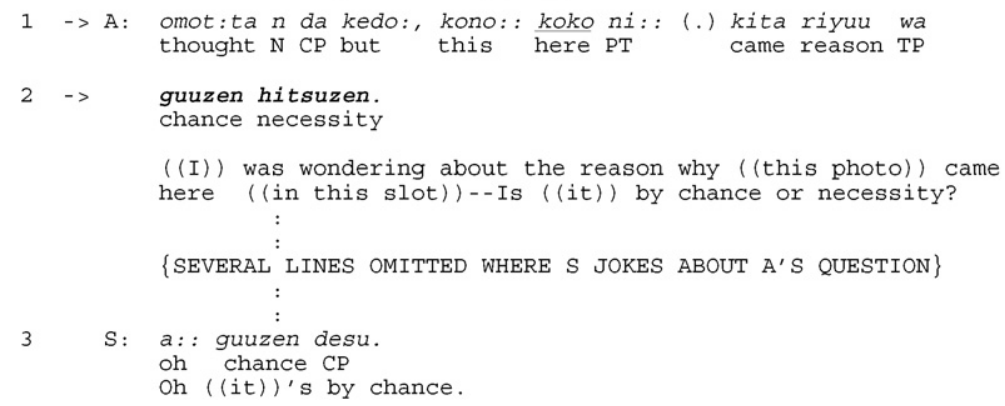

This section has provided an overview of the range of different types of questions observed in the data, with a focus on lexical, morphosyntactic, and prosodic resources used for question formulation in Japanese. The next section discusses what types of social actions are commonly performed with these question utterances.

\subsection{Social actions performed through questions}

The overall distribution of the major types of social actions performed through question utterances identified in the current data is as follows.

Below I discuss each of these actions with examples from the data and provide additional distributional information. 
Table 5

Distribution of social actions being implemented by question type.

\begin{tabular}{|c|c|c|c|c|}
\hline Social action & Polar & Q-word & Alternative & Totals \\
\hline Requesting information & $60 \%(n=53)$ & $39 \%(n=34)$ & $1 \%(n=1)$ & $27 \%(n=88)$ \\
\hline Initiating repair & $50 \%(n=12)$ & $50 \%(n=12)$ & 0 & $8 \%(n=24)$ \\
\hline Requesting confirmation & $100 \%(n=159)$ & 0 & 0 & $49 \%(n=159)$ \\
\hline Offering assessment/opinion, while seeking agreement & $100 \%(n=49)$ & 0 & 0 & $15 \%(n=49)$ \\
\hline Other & $50 \%(n=1)$ & $50 \%(n=1)$ & 0 & $<1 \%(n=2)$ \\
\hline Total & $85 \%(n=274)$ & $15 \%(n=47)$ & $<1 \%(n=1)$ & $N=322$ \\
\hline
\end{tabular}

\subsubsection{Requesting information}

While requesting information may be thought of as a prototypical type of action performed with questions, as shown in Table 5 , it is not the most common type of action performed by the questions observed in the current data. Requesting information is performed with all types of question formats discussed in section 2 except for tag-type questions (i.e., those discussed in section 2.1.1.3). Two most common question formats used for requesting information are polar questions with sentence-final question particles (i.e., those discussed in section 2.1.1.1; 39\%; $n=34$ ) and Q-word questions (39\%; $n=34$ ). If we consider these two types of questions to be more 'prototypical' questions than tag questions and declarative questions, we may say that requesting information is skewed toward more 'prototypical' question formats.

For examples of questions used for requesting information, readers are referred to (1) and (2) above for ka/no-marked polar questions and to (17)-(19), (21)-(28) for Q-word questions.

\subsubsection{Initiating repair}

As is the case with English, question formats are commonly used for other-initiation of repair (OIR; Schegloff et al., 1977) in Japanese. Of the variety of different question formats discussed above, the two most common formats used for OIR is Q-word questions (50\%; $n=12$ ) and declarative questions with sentence-final rising intonation (i.e., those discussed in section 2.1.1.2; 46\%; $n=11$ ). The following examples illustrate these two types of questions used for OIR.

(30) [J002027] ((D, a mother of a teenage daughter, is telling the others that her daughter now wears her old clothes because the type of fashion that used to be popular when D was young is getting popular again now. Miho is the daughter's name.))

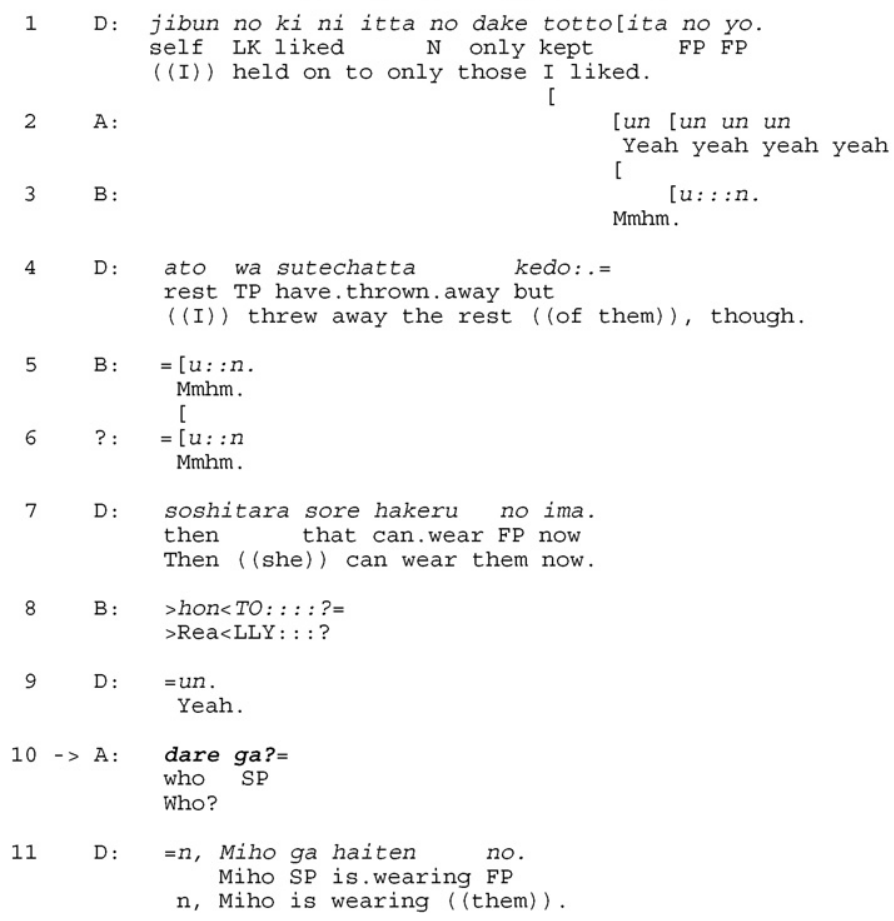


(31) [J002022] ((This segment takes place a few minutes before the segment in (30).))

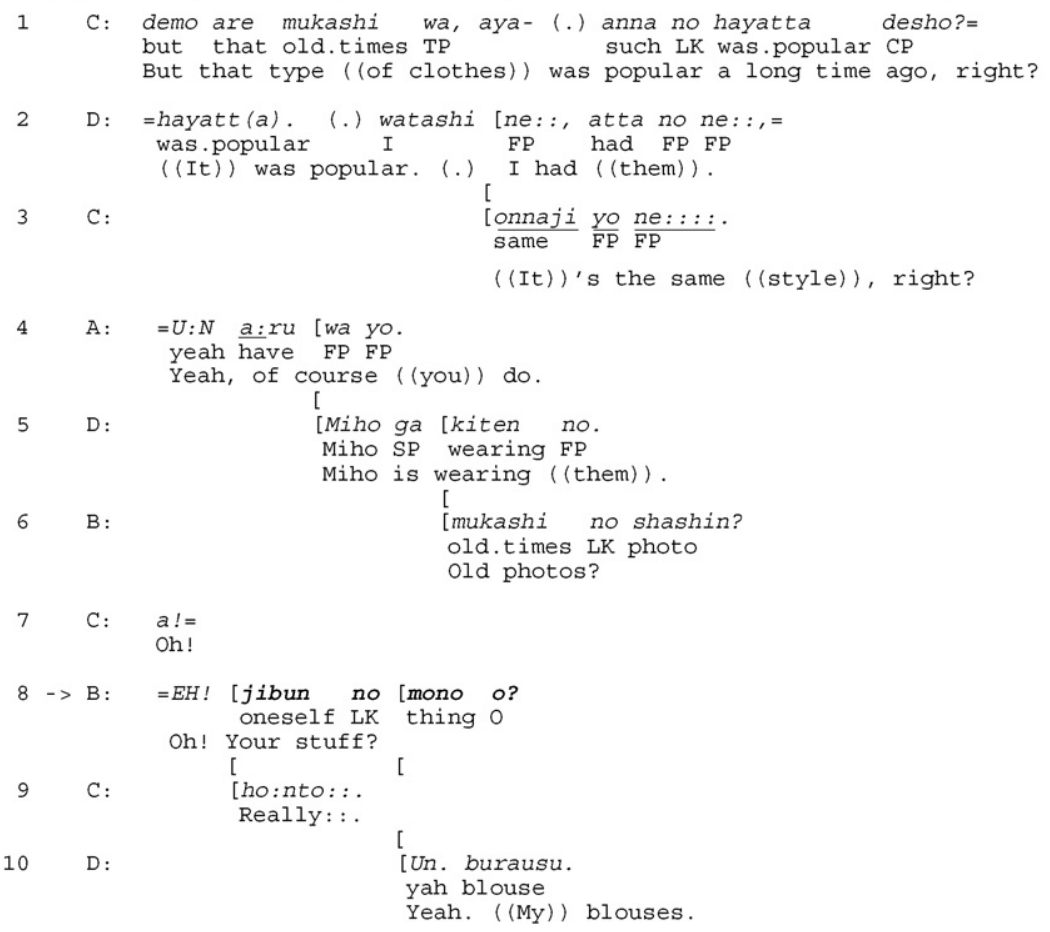

It turned out that, compared to the other languages examined in this project, Japanese has a relatively lower percentage of questions used for OIR ( $8 \%$ in Japanese vs. $15-25 \%$ with many languages). Interestingly, if we look at Q-word questions only, the percentage of OIR in Japanese (25\%) is close to the average among the other 9 languages (28\%). This suggests that the low percentage of OIR in Japanese may stem from its paucity in polar questions. It is not entirely clear why there are fewer OIRs in polar questions in Japanese than in the other languages, but it may have to do with a relatively high percentage of tag-type questions in polar questions in Japanese observed in the current data (nearly 30\% in Japanese vs. 10-20\% with many languages). As discussed below, tag questions (at least in Japanese) are mostly used to present an assertion while seeking agreement. This function of tag questions does not appear to be very compatible with the work that typically gets done by OIR. Thus, a high number of tag-type questions in the current data may have contributed to a low number of OIRs in Japanese.

\subsubsection{Requesting confirmation}

As shown in Table 5, requesting confirmation is by far the most common action performed with questions in the current data. While all the three types of polar questions (interrogative, declarative, and tag-type questions) are used for this function, declarative questions (especially B-event statements) are more commonly used for this function than the others (see Table 6).

In contrast to polar questions, no Q-word question is used for requesting confirmation. The reason is obvious-requesting confirmation is done through presenting a complete proposition for the addressee to confirm or disconfirm, and Q-word questions, by definition, do not present complete propositions.

For examples of questions used for requesting confirmation, readers are referred to (3), (4), (6), (7), (9), and (11) above.

\subsubsection{Offering assessment/opinion while seeking agreement}

In the current data, we observe a skewed distribution of question formats used for offering assessment/opinion while seeking agreement. $88 \%$ of the questions used for this function are tag-type questions. This may account for a high percentage of questions performing this action identified in the Japanese data compared to the other languages (15\% in Japanese vs. an average of $5 \%$ among the other 9 languages). As discussed above, the Japanese data contain a relatively high

Table 6

Distribution of sub-types of polar questions used for confirmation request.

\begin{tabular}{ll}
\hline Polar Q. type used for confirmation request & Percentage \\
\hline Interrogative & $27 \%(n=42)$ \\
Declarative & $50 \%(n=80)$ \\
Tag & $23 \%(n=37)$ \\
Total & $100 \%(n=159)$ \\
\hline
\end{tabular}


number of tag-type questions. It may thus be natural to see a higher percentage of questions devoted to offering assessment/ opinion while seeking agreement in Japanese than in the other languages.

Most of the examples of tag-type questions presented in section 2.1.1.3 illustrate this function ((8), (10), (12), and (13)). It should be noted, however, that tag-type questions are not the only type of question format used for this function. In the following fragment, for example, a negatively-formatted polar question is used to convey an assertion of the opposite polarity, i.e., affirmative, while seeking agreement from the addressee. This is an instance of what Koshik (2005) has called "yes/no reverse polarity questions".

\section{(32) [J006031] ((The participants are discussing the negative impact on children of a TV} commercial in which a beautiful woman burps loudly in public.))

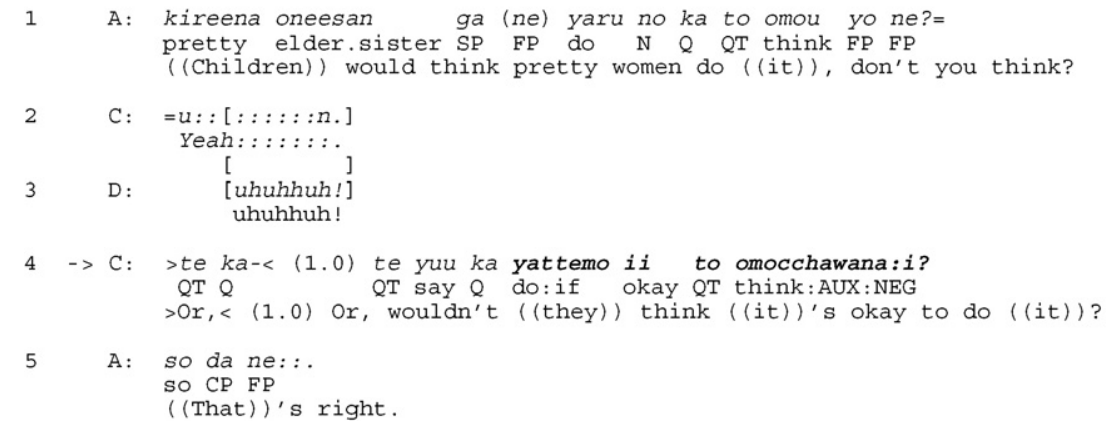

Here, the negative polar question, yattemo ii to omocchawana:i? 'Wouldn't ((they)) think ((it))'s okay to do ((it))?', is used to convey a reserve polarity assertion, i.e., yattemo ii to omocchau '((They)) would think ((it))'s okay to do ((it))', while seeking agreement from the addressee.

This section examined the range of different types of social actions performed through questions observed in the data. The next section discusses the range of methods whereby questioners select whom to respond to their questions.

\subsection{Next speaker selection}

Questions are a prime example of an adjacency pair first pair-part, which makes the addressee's response a relevant next action (Schegloff and Sacks, 1973). This means that, when a question is brought to completion, the person addressed by the questioner is expected to take a turn and respond. While this operation of turn-taking may seem unremarkable, one should bear in mind that, in multiparty conversation where there are more than one person that can be addressed by the current speaker, the questioner needs to work to indicate which current non-speaker(s) the question is being addressed to. There are a number of resources that questioners can use to do this work (Sacks et al., 1974; Lerner, 2003), including the use of address terms, eye gaze, and the addressee's "domain of authority", i.e., through formulating a question regarding a matter that a particular addressee has authority over or knowledge about (e.g., B-event statements).

In the current data, an overwhelming majority of questions clearly select next speakers (99\%; $n=297) .{ }^{4}$ Of these, only $4 \%$ $(n=11)$ make use of an address term. Questions are asked about a matter that falls within a particular addressee's domain of authority in $52 \%$ of the time $(n=164)$. Gaze appears to be the most robust resource utilized for next speaker selection in the current data; $87 \%$ of questions ( $n=275$ ) are accompanied by the speaker's gaze at the addressed recipient. ${ }^{5}$ The percentage of the questions accompanied by the speaker's gaze is the highest in Japanese among the ten languages examined in the project.

Though its use is not as common as those resources mentioned above, there is one other method for next speaker selection observed in the data that is worth mentioning here. It concerns the use of different registers. ${ }^{6}$ Broadly speaking, there are two registers commonly used in Japanese conversation - the polite register (keetai or desu/masu-style) and the plain register (jootai) - and different verb forms are used to indicate in which register the speaker is speaking. Generally, the plain register is used among friends and family members, while the polite register is used when a speaker is speaking to someone to whom s/he has some social distance (e.g., someone that s/he has met for the first time, social superiors like professors, bosses, etc.). Consider, then, the following fragment taken from a conversation between two married couples. Throughout this conversation, Y, the wife of the host couple, consistently uses the polite register when she addresses the guest couple ( $\mathrm{M}$ - husband, $\mathrm{S}$ - wife). When she addresses her husband (K), on the other hand, she consistently uses the plain register. In line 5 of the following fragment, then, Y produces a question in the polite register indicated by the polite form of the copula desu.

\footnotetext{
${ }^{4}$ All the ten conversations from which the data for the present study are taken are multiparty conversations rather than dyadic ones.

5 Uses of address terms, gaze, and addressees' domain of authority are not mutually exclusive. They can be used in conjunction with one another.

6 See also Tanaka (1999) for a description of this method of next-speaker selection.
} 
(33) [J001023] ((The participants have been talking over tea and cake.))

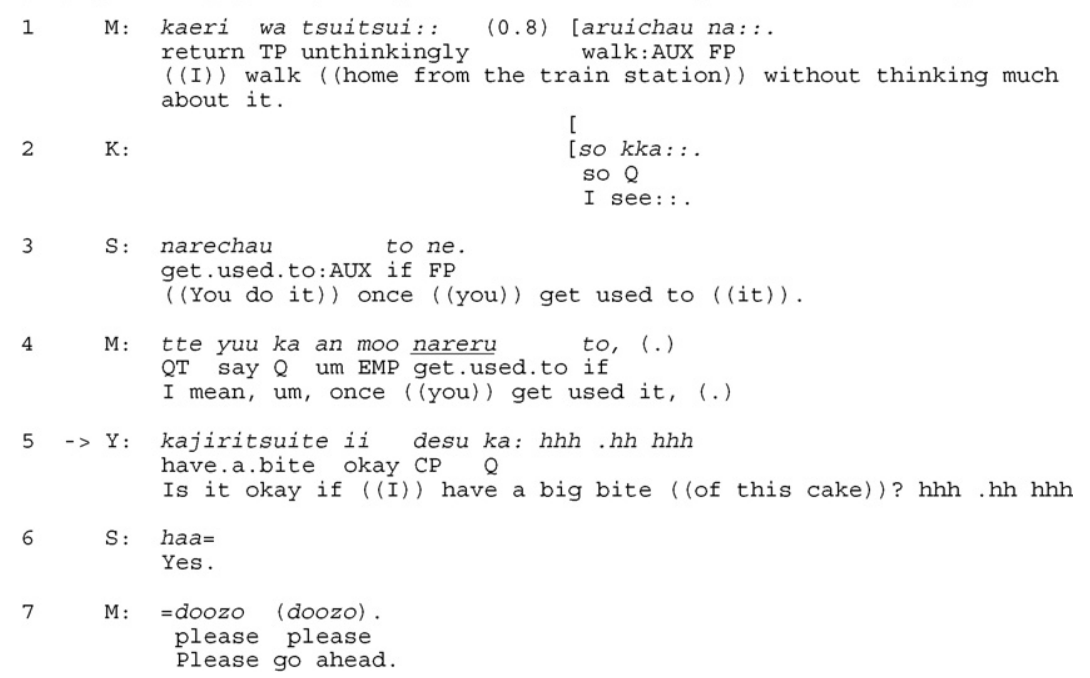

Y's question in line 5 is not accompanied by an address term or gaze-she looks down at a piece of cake in front of her that she is eating when producing the question. The question does not deal with a matter that falls within any particular recipient's domain of expertise or territory of knowledge, either. Also, given that this question is not prompted by anything that was said previously (in fact, it is initiated interruptively in the middle of M's turn), it is not the case here that the questioner selects as next speaker the speaker of a prior turn by virtue of the fact that the question is a response to that prior turn. The major resource for next speaker selection in this case, then, appears to be the use of the polite register. It indicates that Y's question is selecting the guest couple (both $\mathrm{M}$ and $\mathrm{S}$ ) as next speaker (or next speaking party, to be precise) rather than her husband $(\mathrm{K})$, based on the consistency with which Y uses the polite register when addressing the guest couple. Indeed, both $\mathrm{S}$ and $\mathrm{M}$ respond in the subsequent turns.

This section discussed resources with which the questioner indicates selects who should respond to the question being produced. The next section examines the patterns of fittedness between questions and responses to them.

\subsection{Fittedness}

As Sacks (1992, vol. 1:49) points out, while there are particular grammatical structures that are prototypically associated with questions (e.g., interrogative morphosyntax), there are no such structures for answers. The most powerful resource for an utterance to be heard as an answer is its sequential location, i.e., after a question. It should be noted, however, that not every utterance produced after a question counts as an 'answer' to that question. In the current data, there are a range of utterances produced after questions that $d o$ respond to the preceding questions, but which do not provide an 'answer' (i.e., requested information, including confirmation and agreement) to them. Distributionally, $28 \%(n=89)$ of the questions that make the provision of an answer relevant next receive these 'non-answer responses.' (Table 7).

One common type of non-answer response produced in the next turn is repair initiation. This is observed in (5) above, in which a tag question requesting confirmation (bii tii daburyuu totta sshoo '((You)) took BTW, right?') is responded to with a repair initiation (nihyaku gojuu? '250?'). As seen in this example, however, these repair initiations are often done to pave the way for providing an answer subsequently (e.g., line 5 in (5)). Thus, while repair initiation itself is a non-answer response, it usually does not cancel the relevance of supplying an answer to the prior question.

There is another common type of non-answer response which does cancel the relevance of supplying an answer to the prior question. This is done with a claim of lack of knowledge/information being requested by the question, as seen in (34).

Table 7

Distribution of response types.

\begin{tabular}{ll}
\hline Response type $^{\mathrm{a}}$ & Percentage \\
\hline Answer & $61 \%(n=197)$ \\
Non-answer response & $28 \%(n=89)$ \\
No response & $11 \%(n=35)$ \\
Total & $100 \%(n=321)$ \\
\hline
\end{tabular}

${ }^{\text {a }}$ A response can be made either vocally or visually (e.g., nod, head shake) or both. A visual component is present in $47 \%(n=135)$ of the responses observed in the current data. Of these, nine cases ( $3 \%$ of all responses) have responses made solely through visual conduct. 
(34) [J003013] (( $\mathrm{S}$ is looking at the intricate design of a decorated spoon provided to her by Y.))

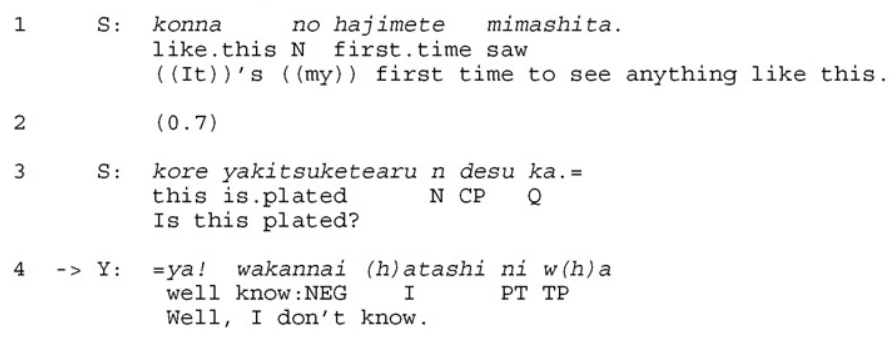

Now, even when responses to questions do provide answers, there are a number of ways in which that gets accomplished. For example, answers to polar questions may be provided in a 'type-conforming' or 'non-conforming' manner (Raymond, 2003). Polar questions, by definition, make relevant a choice between 'yes' and 'no', and answers built with 'yes'/'no' tokens are said to be type-conforming, i.e., conforming to the constraints set by the question format. Tokens used in typeconforming answers in Japanese include such confirming (i.e., 'yes') forms as un, hai, and ee, and disconfirming (i.e., 'no') forms such as ie, iie, iya, and uun. In the current data, an overwhelming majority of type-conforming 'yes'-answers take the form of $u$, with varying degrees of vowel stretch, e.g., $u$ ::n. A majority of type-conforming 'no'-answers, on the other hand, take the form of iya and uun. It is worth noting that, while a 'yes'-form is often used as a stand-alone token in response to a question (e.g., (35)), a 'no'-form rarely constitutes a whole turn by itself. In most cases, a 'no'-token is accompanied by a subsequent turn component, which typically provides an account for the disconfirming response, as seen in (36).

(35) [J009014] ((K, who has never used electronic airline tickets, asks about how to use them.))

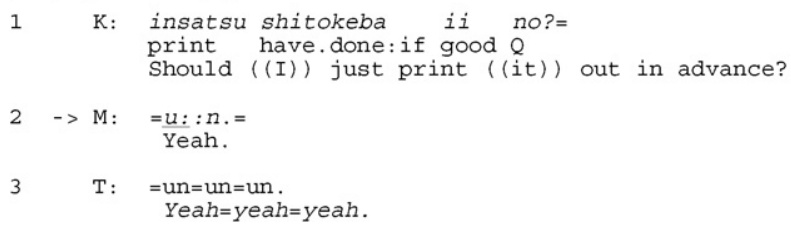

(36) [J001028] ((Ya in line 3 is a variant of $i y a)$.

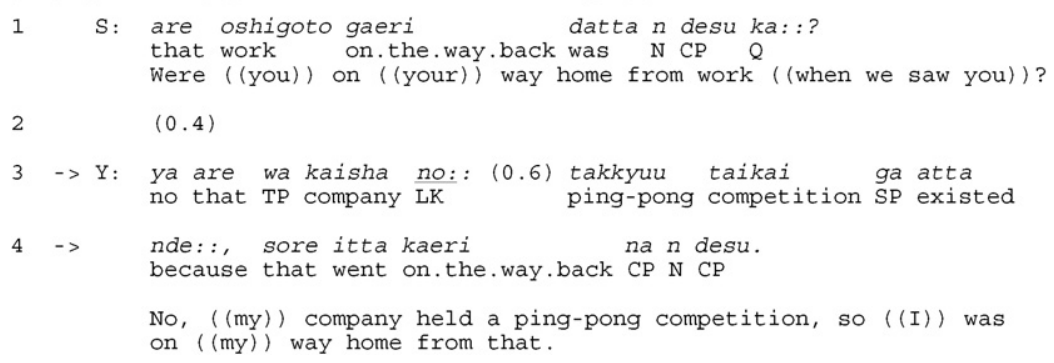

The fact that a 'no'-token rarely appears on its own and is often accompanied by an account suggests that Japanese speakers orient to the dispreferred nature of a disconfirming answer as English speakers do (Ford, 2001). ${ }^{7}$

Let us now turn to non-conforming answers. Non-conforming answers are 'answers' in that, unlike non-answer responses, they provide confirmation/disconfirmation to the preceding questions. However, they do so with a means other than offering 'yes'/'no'-tokens. One such means commonly observed in the current data is to repeat a part (or whole) of the prior question. In Japanese, this is typically done with a repeat of the predicate (e.g., verb, adjective, etc.) of the preceding question, as seen in the following fragments.

\footnotetext{
${ }^{7}$ Note also that, while a 'no'-token can be used for a confirming answer to a negatively-formatted question in English (e.g., A: You don't like tomatoes? B: No.), the same does not hold in Japanese. A 'yes'-token is used for a confirming answer in Japanese irrespective of the polarity of the question. The following provides an example of a 'yes'-token used for a confirming answer to a negatively-formatted question.

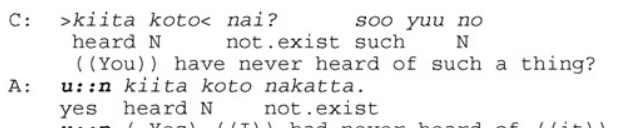


(37) [J004004]

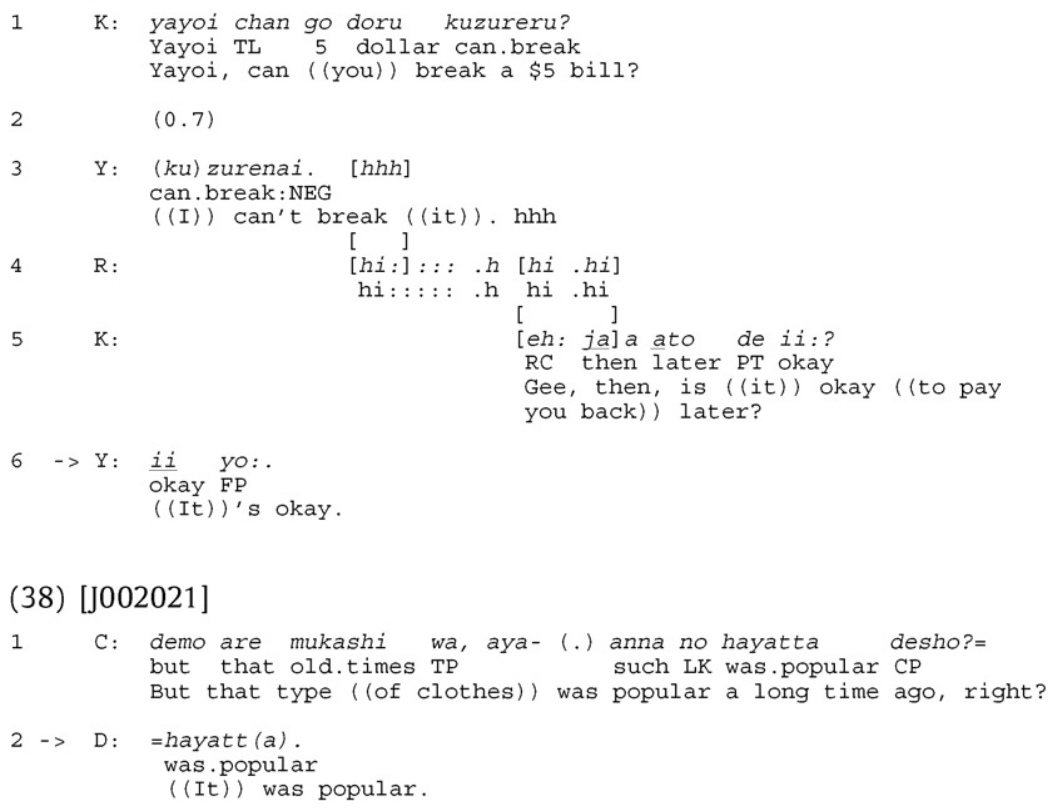

A repeat answer that conveys disconfirmation takes the form of repeating the predicate used in the question and adding the negative morpheme nai to it. This is observed in the following fragment (line 3 of (37) also exemplifies this).

(39) [J006001] ((Yoru to kiri 'Night and mist' is the Japanese title of a book by Austrian psychologist Viktor E. Frankl. Its English title is “Man's Search for Meaning”.)

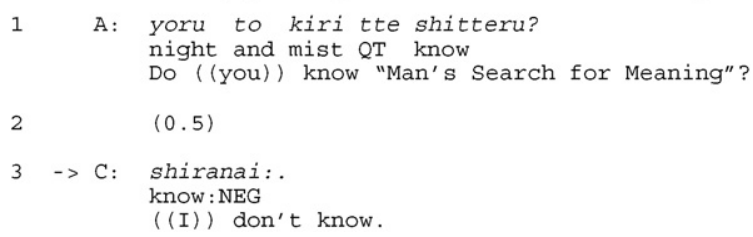

Distributionally, repeat answers are more frequent in Japanese than in English and some other languages examined in this project, including Danish, Dutch, Italian, and Korean (18\% in Japanese vs. an average of $9 \%$ in the other 5 languages). Despite a relatively high percentage of repeat answers, they are not the default type of answers to polar questions, as 'yes/no'-type answers are much more frequent (59\%) (see Table 8). Thus, the situation is different from that in languages like Tzeltal, where repeat answers are used more frequently than 'yes'/'no'-type answers (65\% vs. 35\%) and thus appear to be a basic means of answering polar questions.

It is not clear at this point what motivates the answerer's choice between 'yes/no'-type answers and repeat answers in Japanese. A cursory observation of the data suggests that repeat answers tend to be used when the question addresses a matter that the answerer has some sort of epistemic authority over. This remains as yet speculative, and future research is needed to confirm (or disconfirm) it.

Table 8

Distribution of answer form.

\begin{tabular}{ll}
\hline Answer form & Percentage \\
\hline Yes/no type answer & $59 \%(n=107)$ \\
Repeat & $18 \%(n=32)$ \\
Soo ('Right') & $8 \%(n=15)$ \\
Combination of Yes/No + Repeat & $7 \%(n=12)$ \\
Combination of Yes/No + Soo ('Right') & $<1 \%(n=1)$ \\
Tabun ('Probably') & $1 \%(n=2)$ \\
Transformative answer & $7 \%(n=13)$ \\
Total & $100 \%(n=182)$ \\
\hline
\end{tabular}

a See fragments (40) and (41) for examples of transformative answers. 
I will discuss one other type of non-conforming answer observed in the data before closing this section. Consider the following fragment.

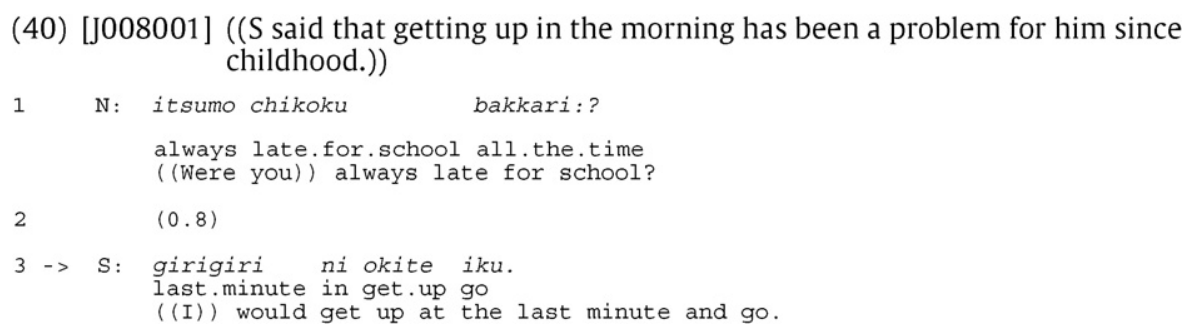

Here, neither a 'yes'/'no' token nor a repeat is used in the answerer's turn. Yet, the answerer produces an utterance that in effect provides an 'answer', i.e., disconfirmation, to the preceding question. Stivers and Hayashi (2010) argue that the answerer uses this type of response to convey a problem with the preceding question's design or its agenda. In this case, the agenda of N's question focuses on requesting confirmation about what she thinks is a likely (or even inevitable) consequence of having difficulty getting up in the morning as a child that S mentioned previously. Saying a type-conforming 'no' might potentially undermine S's prior claim (which was somewhat exaggerated) regarding how hard it was for him to get up in the morning. S thus transforms the question into one about how he dealt with the issue of having to go to school in time and answers it in such a way as to maintain his claim that getting up in the morning was still difficult. Stivers and Hayashi (2010) call this type of answer a 'transformative answer'.

This section discussed some aspects of the fittedness between questions and responses to them observed in the Japanese data. As fittedness is a little-studied area, the description provided here is necessarily sketchy. Many interesting issues surrounding the patterns of fittedness remain to be investigated in future research. ${ }^{8}$

\section{Conclusions}

This paper provided an overview of the question-response system in Japanese, with a focus on the lexical/ morphosyntactic/prosodic resources used for question formulation, the range of action types commonly performed with question-formatted utterances, the kinds of methods used for next speaker selection, and the patterns of fittedness between questions and their responses. While I believe the descriptions presented in this paper have covered basic aspects of the question-response system in Japanese, they are by no means exhaustive. I hope this will serve as a point of departure for more extensive and more detailed studies on various phenomena related to the organization of the question-response sequence in Japanese interaction.

\section{Appendix A}

Abbreviations used in the interlinear gloss:

$\begin{array}{llllll}\text { AUX } & \text { Auxiliary } & \text { CP } & \text { Copula } & \text { EMP } & \text { Emphasis marker } \\ \text { EXCL } & \text { Exclamation } & \text { FP } & \text { Final particle } & \text { LK } & \text { Linking particle } \\ \text { MIM } & \text { Mimetics (sound effect) } & \text { N } & \text { Nominalizer } & \text { NEG } & \text { Negative morpheme } \\ \text { O } & \text { Object particle } & \text { POL } & \text { Polite register } & \text { PST } & \text { Past tense } \\ \text { PT } & \text { Particle } & \text { Q } & \text { Question particle } & \text { QT } & \text { Quotative particle } \\ \text { RC } & \text { Response cry } & \text { RP } & \text { Retrospective particle } & \text { SP } & \text { Subject particle } \\ \text { TAG } & \text { Tag question } & \text { TL } & \text { Title } & \text { TP } & \text { Topic particle }\end{array}$

\section{References}

Clancy, Patricia, 1980. Referential choice in English and Japanese narrative discourse. In: Chafe, W. (Ed.), The Pear Stories: Cognitive and Linguistic Aspects of Narrative Production. Ablex, Norwood, pp. 127-202.

Ford, Cecilia E., 2001. At the intersection of turn and sequence: negation and what comes next. In: Selting, M., Couper-Kuhlen, E. (Eds.), Studies in Interactional Linguistics. John Benjamins, Amsterdam/Philadelphia, pp. 51-79.

Hinds, John, 1982. Ellipsis in Japanese. Linguistic Research Inc., Edmonton.

\footnotetext{
${ }^{8}$ For example, Hayashi (2007) examines the use of the response token $e$ at the beginning of an answer to a question, and shows that eh-prefacing is used to index the preceding question's departure from the answerer's expectation or supposition with regard to its relevance or appositeness in the local context.
} 
Heritage, John, Roth, Andrew L., 1995. Grammar and institution: questions and questioning in the broadcast news interview. Research on Language and Social Interaction 28, 1-60.

Iwasaki, Shoichi, 1993. Functional transfer in the history of Japanese language. In: Clancy, P. (Ed.), Japanese/Korean Linguistics, vol. 2. CSLI, Stanford, pp. 20-32.

Iwasaki, Shoichi, 2002. Japanese. John Benjamins, Amsterdam/Philadelphia.

Koshik, Irene, 2005. Beyond Rhetorical Questions: Assertive Questions in Everyday Interaction. John Benjamins, Amsterdam/Philadelphia.

Kuno, Susumu, 1973. The Structure of the Japanese Language. MIT Press, Cambridge, MA.

Labov, William, Fanshell, David, 1977. Therapeutic Discourse: Psychotherapy as Conversation. Academic Press, New York.

Lerner, Gene, 2003. Selecting next speaker: The context-sensitive operation of a context-free organization. Language in Society 32, $177-201$.

Makino, Seiichi, Tsutsui, Michio, 1986. A Dictionary of Basic Japanese Grammar. Japan Times, Tokyo.

Martin, Samuel E., 1975. A Reference Grammar of Japanese. Yale University Press, New Haven.

Maynard, Senko K., 1992. Cognitive and pragmatic messages of a syntactic choice: the case of the Japanese commentary predicate $n(0)$ da. TEXT 12 (4), 563-613.

McGloin, Naomi H., 1980. Some observations concerning no desu expressions. Journal of the Association of Teachers of Japanese 15, 117-149.

Raymond, Geoffrey, 2003. Grammar and social organization: yes/no interrogatives and the structure of responding. American Sociological Review 68, 939-967.

Sacks, Harvey, 1992. Lectures on Conversation, 2 vols. Blackwell, Oxford.

Sacks, Harvey, Schegloff, Emanuel A., Jefferson, Gail, 1974. A simplest systematics for the organization of turn-taking for conversation. Language 50, $696-735$.

Schegloff, Emanuel A., Jefferson, Gail, Sacks, Harvey, 1977. The preference for self-correction in the organization of repair in conversation. Language 53, 361-382.

Schegloff, Emanuel A., Sacks, Harvey, 1973. Opening up closings. Semiotica 8, 289-327.

Shibatani, Masayoshi, 1990. The Languages of Japan. Cambridge University Press, Cambridge.

Stivers, Tanya, Hayashi, Makoto, 2010. Transformative answers: one way to resist a question's constraints. Language in Society $39,1-25$.

Tanaka, Hiroko, 1999. Grammar and social interaction in Japanese and Anglo-American English: the display of context, social identity and social relation. Human Studies 22, 363-395.

Makoto Hayashi is associate professor of Linguistics and East Asian Languages and Cultures at the University of Illinois at Urbana-Champaign. His research examines ways in which language practices employed by Japanese speakers shape, and are shaped by, the organization of talk-in-interaction. 